Risks from Worldwide Terrorism: Mortality and Morbidity Patterns and Trends

K. T. Bogen, E. D. Jones

February 4, 2005 
This document was prepared as an account of work sponsored by an agency of the United States Government. Neither the United States Government nor the University of California nor any of their employees, makes any warranty, express or implied, or assumes any legal liability or responsibility for the accuracy, completeness, or usefulness of any information, apparatus, product, or process disclosed, or represents that its use would not infringe privately owned rights. Reference herein to any specific commercial product, process, or service by trade name, trademark, manufacturer, or otherwise, does not necessarily constitute or imply its endorsement, recommendation, or favoring by the United States Government or the University of California. The views and opinions of authors expressed herein do not necessarily state or reflect those of the United States Government or the University of California, and shall not be used for advertising or product endorsement purposes.

This work was performed under the auspices of the U.S. Department of Energy by University of California, Lawrence Livermore National Laboratory under Contract W-7405-Eng-48. 


\title{
Risks from Worldwide Terrorism: Mortality and Morbidity Patterns and Trends
}

\author{
Kenneth T. Bogen ${ }^{1}$ and Edwin D. Jones ${ }^{2}$ \\ ${ }^{1}$ Environmental Science Division, and \\ ${ }^{2}$ Risk and Response Management Program \\ Lawrence Livermore National Laboratory \\ University of California, Livermore, CA 94550, USA
}

January 25, 2005

*To whom correspondence should be addressed at: Environmental Science Div. (L-396), Lawrence Livermore National Laboratory, 7000 East Avenue, Livermore, CA 94550-9900, USA, TEL: (925) 422-0902, FAX: (925) 424-3255, NET: bogen@LLNL.gov.

Abbreviations: $\mathrm{AE}=$ adverse event, $\mathrm{ANOCOVAR}=$ analysis of covariance, $\mathrm{CL}=$ confidence limits, GEV = generalized extreme value, GP = generalized Pareto, HOT = highly optimized tolerance, MIPT = Memorial Institute for the Prevention of Terrorism. 


\begin{abstract}
Worldwide data on terrorist incidents between 1968 and 2004 gathered by the RAND corporation and the Oklahoma City National Memorial Institute for the Prevention of Terrorism (MIPT) were assessed for patterns and trends in morbidity/mortality. The data involve a total of 19,828 events, 7,401 “adverse" events (each causing $\geq 1$ victim) , 91,346 cases of casualty (either injury or death) and 25,408 deaths. Analyses revealed a number of interesting patterns and apparently significant trends. Most terror-related adverse events, casualties and deaths involved bombs and guns. Weapon-specific patterns and terror-related risk levels in Israel (ISR) have differed markedly from those of all other regions combined (AOR). ISR had a fatal fraction of casualties about half that of AOR, but has experienced relatively constant lifetime terror-related casualty risks on the order of $0.5 \%$-a level 2 to 3 orders of magnitude more than those experienced in AOR, which have increased $~ 100$-fold over the same period. Individual event fatality has increased steadily, the median increasing from 14 to $50 \%$. Lorenz curves obtained indicate substantial dispersion among victim/event rates: about half of all victims were caused by the top $2 \%(10 \%)$ of harm-ranked events in OAR (ISR). Extreme values of victim/event rates were found to be well modeled by classic or generalized Pareto distributions, indicating that these rates have been as predictable as similarly extreme phenomena such as rainfall, sea levels, earthquakes, etc. This observation suggests that these extreme-value patterns may be used to improve strategies to prevent and manage risks associated with terror-related consequences.
\end{abstract}

Key words: Extreme value, homeland security, modeling, Pareto 


\section{Introduction}

A burgeoning literature has developed concerning trends and patterns pertaining to global terrorism and strategies to combat it (e.g., Fowler, 1981; Cordes et al., 1984; Hoffman, 1997,1998; Frey and Leuchinger, 2003). Since 2001, the RAND corporation and the Oklahoma City National Memorial Institute for the Prevention of Terrorism (MIPT) have worked to prepare an online database of terrorism incidents to help researchers, analysts, and others working to prevent terrorism (Ellis, 2004). The resulting MIPT Terrorism Database System now makes available comprehensive information and intelligence on terrorism, including two RAND databases that provide raw information concerning dates and locations of specific events and associated numbers of victims: the RAND Terrorism Chronology Database, and the RANDMIPT Terrorism Incident Database (MIPT, 2004a). The first of these databases records international terrorist incidents that occurred between 1968 and 1997, while the second records domestic as well as international terrorist incidents that occurred from 1998 to the present (MIPT, 2004b). All information in these databases is stated as being obtained from open source materials (e.g., newspapers) after review to verify accuracy (MIPT, 2004c).

The database defines terrorism not by the identity of the perpetrators, but by the nature of the act to be "violence calculated to create an atmosphere of fear and alarm" to coerce others into action or inaction not otherwise undertaken, generally directed against civilian targets, with motives that are political expressed through actions generally carried out in a way that achieves maximum publicity (MIPT, 2004b). This definition of terrorism is similar to that used by others studying terrorism, e.g. Frey and Leuchinger (2003) define terrorists as "perpetrators [who] (i) use force on civilians; (ii) act in an unofficial capacity ... in particular, not [as] part of the national army and ... not wear[ing] any national uniform; (iii) want to achieve political goals; 
(iv) aim to have far-reaching effects beyond the immediate victims, particularly through the media."

The two RAND-MIPT data sets pertaining to terrorist incidents from 1968 to the present (referred to hereafter jointly as the RAND-MIPT database) summarize a wide array of publicly accessible data that may be used, certainly as a starting point, to characterize historical patterns and possible trends concerning, among other things, mortality and morbidity risks imposed by terrorism. Curiously, however, the providers of these raw data warn that the database they have made public is "intended only to aid those seeking to better comprehend terrorism and should not be used as a tool for any sort of analysis, predictive or otherwise" (MIPT, 2004c). This caveat suggests that patterns or trends that may be evident in the data may be spurious, or artifacts of data collection methods used, etc. The present study was undertaken to assess this possibility by examining the data for patterns and trends in a way that accounts for statistical error as well as the major discontinuity starting in 1998 in the definition used for included events.

Primary endpoints examined were rates of mortality and morbidity due to terrorist events over time and per event, and how these rates may vary by geographic region, target, and weapon used. Extreme-value distributions of victims/event were also examined. If extreme values of a phenomenon arise from independent stochastic variation acting on a homogeneous underlying mechanism, their statistical distribution should be a member of a generalized extreme value family of distributions readily characterized by statistical methods (Coles and Pericchi, 2003). This type of analysis is often done on data pertaining to temperature, wind speed, rainfall, sea and river levels, wave heights, material breaking strength, earthquakes, etc. Irregularities or discontinuities in extreme-value distributions for data on victims/event exhibited in meaningful subsets of the RAND-MIPT database would indicate underlying non-homogeneities due not 
likely to chance, but rather to mixed underlying mechanisms, sampling bias, effects of unidentified covariates, data inconsistencies, or other factors. Methods described below were used to assess RAND-MIPT data along these lines. Apparent trends and patterns revealed by this analysis are summarized in Results, followed by a discussion of potential key limitations and implications.

It is emphasized that analyses reported here were done using RAND-MIPT web-accessible data described (at the time this report was prepared) as being last updated on November 24, 2004 (MIPT, 2004a, 2004c). Historical data made available from this source is subject to occasional modification and is updated regularly with new information, which may affect results of any new study otherwise identical to the one reported here, based on data collected and analyzed as described below.

\section{Methods}

The RAND-MIPT database as of mid-December, 2004, was divided into two different datasets: incidents collected between 1968 and 1997 (the "RAND Terrorism Chronology") only account for international terrorism (incidents in which the perpetrators cross national boundaries strike targets, select domestic targets with a foreign state association or create an international incident by attacking airline passengers or equipment, where as data from 1998 to the present include domestic terrorism incidents (perpetrated by local nationals against a purely domestic target) as well as international incidents (MIPT, 2004b). For the present study, these data were divided into 5-y periods starting in 1968-1972, with data for 2005-2007 during the final period estimated by linear extrapolation of data obtained for 2003-2004. 
Database variables addressed in the present study were: time period, casualties (the sum of injuries and/or deaths), deaths, "adverse" events (AEs, meaning terrorist events that caused one or more casualties), world region (Africa, East Central Asia, Eastern Europe, Israel, Latin America, Near East [excluding Israel and the Occupied Territories], North America, the Occupied Territories, South Asia, Southeast Asia and Oceana, and Western Europe), weapon type (Biological, Bomb, Chemical, Fire, Guns, Remote-controlled Bomb, Bladed Weapons such as knives, and Other), and target (Airport \& Airlines, Business, Diplomatic, Government, Military, Police, Private Citizens/Property, Religious Figures \& Institutions, Transportation, and Other), where "Other" denotes unknown, unavailable, unidentified, or otherwise not included in the database.

The following terms and notation are used: "event" = terrorism "incident", $F_{\text {adv }}=$ fraction of events that caused casualties, $F_{\text {fat }}=$ "fatal fraction" of adverse-event-induced casualties (i.e., fraction of casualties representing deaths), and $\mathrm{X}_{0}(=-a / b)=$ the abscissa intercept of a linear fit $\mathrm{Y}=a+b \mathrm{X}$ conditional $\mathrm{Y}=0$. The fraction $F_{\mathrm{fat}}$ is referred to as an "unweighted" average when calculated as $F_{\text {fat }}=k^{-1} \square m_{i} / c_{i}$, and as a "casualty-weighted" average when calculated instead as $F_{\text {fat }}=\square m_{i} / \square c_{i}=\square w_{i}\left(m_{i} / c_{i}\right) / \square w_{i}$ with weights $w_{i}=c_{i}$, where $m_{i}=$ deaths and $c_{i}=$ casualties per $i$ th adverse event $\mathrm{AE}_{i}$, and summation $(\square)$ is over all $k$ corresponding $\mathrm{AE}_{i}, i=1, \ldots, k$ within a specific period or region. The weighted mean fraction $F_{\text {fat }}$ is thus synonymous with the ratio of total deaths to total casualties within one or more specified categories.

Significance of differences in means, of linear trends, of differences among linear-regression slopes and intercepts, of outlying data, and of outliers among data fit by linear regression were assessed, respectively, by 2-tail t-test, by 2-tail t-test for non-zero linear regression slope, by analysis of covariance (ANOCOVAR), by 2-tail F-test for reduced variance, and by F-test for 
reduced goodness of linear fit (Snedecor and Cochran, 1989). In cases of unequal variance assessed by 2-tail F-test using a critical value of $\square=0 . .05$, significance of a difference in means was assessed using Welch's approximate 2-tail t-test (Kendall and Stuart, 1979). P-values obtained for related sets of multiple tests (e.g., region-specific regression slopes for events plotted against period) were transformed to corresponding adjusted values ( $\mathrm{p}_{\text {adj }}$ ) to account for multiple independent tests using Hommel's Bonferroni-type adjustment (Wright, 1992). Significance of the difference between empirical distributions for two samples each of size $\geq 100$ was assessed using Smirnov's approximate Kolmogorov 2-sample test (Kim, 1969).

The relative value of focusing preventive efforts on extreme events that yield very many victims requires knowledge of the extent to which such extreme events may contribute disproportionately to the total number of victims. The Lorenz curve, and corresponding Gini coefficient $(G)$ of disparity are typically used to characterize income and resource inequality in econometric and ecologic studies. A Lorenz curve $C$ plots the inverse cumulative relative frequency function for $n$ ordered relative magnitudes, $f_{i}=x_{(i)} / \square x_{i}, i=1, \ldots, n$, and so plots (vs. $i / n$ ) the cumulative relative contribution of $x_{(i)}$ toward the $n$-sample mean value of $x$, for which an unbiased sample estimate of the corresponding inequality index $G$ is given by $[n /(n-1)]\left[1-\left(\mathrm{A}_{C} / 2\right)\right]$ where $\mathrm{A}_{C}$ is the area beneath $C$ (Dagum, 1980; Damgaard and Weiner, 2000). These measures were used to characterize the relative contribution of extreme events toward total deaths and total casualties due to terrorism over the entire study period.

If generated by a homogeneous independent stochastic process, extreme values of a rate $(X)$ of victims (deaths or casualties) per event are expected to have a generalized extreme value (GEV) distribution, such that the corresponding likelihood of exceedance above a selected threshold $u$ will follow a generalized Pareto (GP) distribution, 


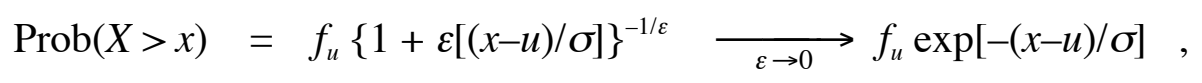

where $f_{u}=\operatorname{Prob}(X>u) ; \square$ and $\square$ are the GP-model scale and shape parameters, respectively; and a further Poisson assumption implies that the level $x_{m}$ exceeded on average once every $m$ events or observations is just $x_{m} \mid\left\{\operatorname{Prob}\left(X>x_{m}\right)=1-p_{0}\right\}$, where $P_{0}=\operatorname{Prob}(z e r o$ exceedances) $\square$ the mean threshold-exceedance rate of $\square=1 / m$ (Coles, 2001; Coles and Pericchi, 2003). In the present study, GP-model parameters, their confidence limits (CL), and return levels $x_{m} \mid u$ were estimated by maximum likelihood methods, and confidence limits on $x_{m} l u$ were estimated using the delta method, as previously described (Coles, 2001), except that corresponding likelihood equations were modified to reflect an exact Poisson assumption that $P_{0}=\exp (-\square)$. Each GP fit included a likelihood ratio test of the null hypothesis that $\square=0$, and significance value $p_{\square \neq 0}$ of the corresponding deviance statistic for that test (Coles, 2001). GP fits were obtained conditional on $\square=0$ in each case the corresponding initial fit yielded $\mathrm{p}_{\mathbb{E} 0}>0.01$.

Data analysis and model fitting was done using Mathematica $^{\circledR}$ and related computer software (Wolfram, 1999; Bogen, 2004).

\section{Results}

Weapons and targets. Occurrence rates and impacts on morbidity and mortality of all 25,303 events included in the data base studied are summarized by period in Table 1, by weapon type for all regions combined in Table 2, and by weapon type for Israel in Table 3. For all regions combined over the entire period studied, $\sim 80 \%$ of adverse events and related casualties, and $\sim 70 \%$ of related deaths involved bombs and guns (Table 2). While bombs caused about 5 times as many casualties and twice as many deaths as did guns, adverse events involving guns have on average been about $\sim 2.5$ times more lethal those involving bombs (Table 2). The fatal 
fraction $\left(F_{\text {fat }}\right)$ of all casualties from adverse events was greatest (nearly $\left.80 \%\right)$ for the "other" weapons category (Table 2), which for example includes all airplane-related deaths from events on September 11, 2001, for which $F_{\text {fat }}=100 \%$.

Weapon-specific morbidity and mortality rates from events in Israel (Table 3) differ substantially from those in all other regions combined. In Israel from 1968-2004, bombs and guns were involved in only $\sim 75 \%$ of adverse events, but accounted for $>90 \%$ of related casualties and $\sim 86 \%$ of related deaths (Table 3 ). In Israel during this period, bombs caused about 10 times as many casualties and 8 times as many deaths as did guns (i.e., the bomb-to-gun potency ratio in Israel has been about twice that of all other regions combined); and while each adverse event involving guns was on average about twice as lethal as those involving bombs, casualty-weighted fatal fraction $\left(F_{\text {fat }}\right)$ of all casualties by guns and that by bombs were nearly equal (Table 3). The latter fraction for gun-related events in Israel $\left(F_{\text {fat }}=17.5 \%\right)$ is approximately one third the size of the corresponding fraction (51.2\%) for all other regions combined (Tables 2-3). The percent of total terrorism-induced deaths due to bombs from 19682004 in Israel vs. all other regions combined was $77.1 \%$ vs. $48.1 \%$, whereas this comparison for guns is $9.3 \%$ vs. $22.9 \%$. The Israeli figure for bombs is the greater than that of any other region (the Near East coming in second at 71.0\%, and North America last at 10.3\%). Only North America has experienced a percent of gun-induced terrorism-related deaths (1.2\%) smaller than that of Israel.

A few period-specific rates by weapon and target clearly changed starting in 1998, likely reflecting the inclusion of domestic events in the database starting in 1998. For example, periodspecific fractions of events prior to 1998 vs. after 1997, respectively, were for events involving: guns $<40$ vs. $>40 \%$, unspecified weapons $>13 \%$ vs. $<13 \%$, private citizens/property $<9 \%$ vs. 
$>22 \%$, government targets $<3 \%$ vs. $>20 \%$, and police targets $<2 \%$ vs. $>6 \%$. Some significant overall trends were detected, however. Period-specific fractions of events over 5-y periods starting in 1968 through 1997 or through 2007, had the following statistically significant trends: those involving bombs fell from 57\% to $40 \%$ through $1997\left(\mathrm{R}^{2}=0.67, \mathrm{p}=0.046\right)$ and through $2007\left(R^{2}=0.58, p=0.029\right)$; those involving diplomatic targets fell from $40 \%$ to $>10 \%$ through $1997\left(R^{2}=0.96, p=0.000024\right)$ and to $<2 \%$ through $2007\left(R^{2}=0.95, p=0.00092\right)$; and those involving airport/airline targets fell from $14 \%$ to $2 \%$ through $1997\left(\mathrm{R}^{2}=0.96, \mathrm{p}=0.000020\right)$ and to $<0.5 \%$ through $2007\left(R^{2}=0.96, p=0.00062\right)$. Similarly significant temporal trends were not observed for corresponding attributable fractions of total casualties or deaths.

Occurrence of total vs. adverse events. No significant trend was found in the occurrence rate of international events worldwide over six 5-y periods (a total of 30 years) from 1968-97 ( $\mathrm{p}=$ 0.16 ), which corresponds to an average ( \pm 1 SEM) rate of $274 \pm 31.8$ events/y. The corresponding mean post-1997 rate has been $1707 \pm 118$ events/y - a rate significantly (6.2-fold) greater than the pre-1998 rate $\left(\mathrm{p}=2 \square 10^{-6}\right)$, clearly reflecting the post-1997 inclusion of domestic terrorism events in the MIPT database. A significant upward temporal trend was observed for the worldwide occurrence of adverse events (Figure 2), though not at a regional level ( $\left.\mathrm{p}_{\mathrm{adj}}>0.05\right)$. Significant upward temporal trends were also observed in the worldwide "adverse" fraction $\left(F_{\text {adv }}\right)$ of all period-specific terrorist events (Figure 3), and in $F_{\text {adv }}$ for Africa, Latin America, Near East (here defined to exclude Israel and the Occupied Territories), and South Asia taken as a "rising" group (Figure 3). However, no trend is evident in $F_{\text {adv }}$ for Israel, or for all other regions combined as a "static" group (Figure 3). Over all periods studied, Israel has experienced the highest mean value of $F_{\text {adv }}(0.60)$, about twice that of the "static" regional 
group, while over this time span the "rising" group has experienced $F_{\text {adv }}$ levels that increased from about that of the "static" group to about that of Israel.

Victim, victims/event and fatality rates. Worldwide casualties and deaths per period due to terrorism have risen steadily over the entire time span studied, with pre-1998 levels (which did not include domestic events), having been about 3- to 4-fold less than post-1997 levels (which did; Figure 4). Corresponding period-specific values of the ratio of total victims to total events show similarly increasing trends, which do not appear to have been affected by the post-1997 inclusion of domestic events in the data base analyzed (Figure 5). In contrast, no temporal trend is evident in pre-1998 data for the ratio of either casualties or deaths to total adverse events (AE), nor is any shift in these rates clearly associated with post-1997 inclusion of domestic events (Figure 6). While worldwide casualty-weighted mean values of $F_{\text {fat }}$ by period show no temporal trend, unweighted values of $F_{\text {fat }}$ (i.e., death-to-casualty ratios for each event grouped by period) have increased steadily over time $(\mathrm{p}=0.001$, Figure 7$)$. Period-specific worldwide $F_{\text {fat }}$ distributions clearly have shifted to the right over time, increasingly including more extreme values (Figure 8). For example, from 1968-72 to 2003-2004, the median value of $F_{\text {fat }}$ increased 0.14 to 0.50 , while the percentage of events in which $F_{\text {fat }}=0$ decreased from $41 \%$ to $27 \%$ (Figure 8).

Casualties/event and casualties/AE rates appear to have been anomalously high during the 1993-97 period, clearly statistically inconsistent with corresponding rates for earlier periods (Figures 5-6). The high rate of casualties/AE in the 1993-97 period explains the anomalously low casualty-weighted mean fatal fraction $\left(F_{\text {fat }}\right)$ of events that also occurred during that period (Figure 7). All of these phenomena are due principally to the 1995 attack using Sarin (nerve gas) 
in multiple subway cars in Tokyo, Japan, injuring at least 5000 but killing only 12 . This single event accounts for nearly all casualties, as well as the very low casualty-weighted mean $F_{\text {fat }}$ ratio, pertaining to the E. Central Asia region (Figure 9) over the entire time span studied. Likewise, the relatively $F_{\text {fat }}$ ratio for North America compared to all other regions (Figure 9) is due primarily to casualties inflicted on Sept. 11, 2001, in New York City, in Washington D.C. and on hijacked American Airlines Flight 77, which all had a 100\% fatality rate.

No single event explains Israel's relatively low casualty-weighted mean $F_{\text {fat }}$ ratio (Figures 910). Although, as mentioned above, $F_{\text {adv }}$ generally has been higher for Israel than for any other region examined (Figure 3), corresponding period-specific deaths/event for Israel vs. other regions combined show (by ANOCOVAR) no significant difference in either slope $(p=0.32)$ or intercept $(p=0.090)$ of linear trend. The latter trend has been significantly positive for the other combined regions ( $\mathrm{p}_{\mathrm{adj}}=0.0016$ ), increasing from approximately 0.4 to 1.6 deaths/event from the first to the last time period examined. Israel's casualty-weighted mean $F_{\text {fat }}$ ratio has remained about half that of other regions combined (Figures 9-10), with the exception of the 1993-97 period in which the ratio for other regions decreased sharply to about the same level as Israel (Figure 10), due primarily to the 1995 event in Tokyo mentioned above. From 1968-2004 in Israel, $F_{\text {fat }}$ values for adverse events involving bombs have been lower, and $F_{\text {fat }}$ values for adverse events involving guns have been remarkably lower, than corresponding $F_{\text {fat }}$ values experienced in all other regions combined, regardless of the casualties/AE rate (Figure 11). Likewise, the percent of gun-related lethal events has been substantially lower in Israel compared to other combined regions, regardless of the number of deaths per lethal event (Figure 12). 
Per capita risks of mortality and morbidity from terrorism. During the period 1968-2004, it is clear that victims/event rates have been substantially higher in Israel than in all other regions combined (Figure 13). During this period, the Israeli population comprised an average of 0.093\% of the population of all other regions combined, yet MIPT-RAND data indicate that over this period Israel has hosted $4.0 \%$ of all terrorist events, $5.3 \%$ of all terrorism-related deaths, and $9.2 \%$ of all terrorism-related casualties, which rates are approximately 40, 60 and 100 times the corresponding rates expected based solely on relative population.

Israel similarly has experienced far greater per capita lifetime (70-year) equivalent risks of mortality $\left(R_{\text {fat }}\right)$ and morbidity $\left(R_{\text {cas }}\right)$ due to terrorism over this period, compared to all other nonNear-Eastern regions combined (Figure 14). From 1968-1997 (prior to the inclusion of domestic events in the MIPT-RAND database), $R_{\text {cas }}$ and $R_{\text {fat }}$ had mean values of 2,400 per million $(\sim 0.2 \%)$ and 410 per million $(\sim 0.04 \%)$, respectively - values 190 - and 150 -fold greater, respectively, than corresponding risks experienced during the same period in all other non-Near-Eastern regions combined. Corresponding levels of per capita risk experienced in the Near East outside of Israel and the Occupied Territories over all periods have ranged between levels experienced in Israel and those experienced in non-Near-Eastern regions, while rates experienced in the Occupied Territories remained at Near-Eastern levels from 1968-92 but then jumped approximately to Israeli levels thereafter (Figure 14).

Extreme values of victims/event. Lorenz curves for the cumulative fraction of victims of terrorist events during 1968-2004 (Figure 15) indicate substantial heterogeneity in victim/event rates in Israel ( $G=0.600$ for deaths, 0.689 for casualties), and even more so in all other regions combined ( $G=0.717$ for deaths, 0.807 for casualties). The Lorenz curves for each region also 
have quite different upper-right patterns, indicating very different contributions to victim totals by extreme events that caused the greatest numbers of victims (Figure 15). For example, from these curves it is evident that during this period that the top $10 \%$ of events in Israel ranked by harmfulness caused about half of all victims there, whereas about half of all victims were caused by the top $2 \%$ of all similarly ranked events in all other regions combined.

Absent any clear indication of a pre-1998 vs. post-1997 discontinuity (e.g., due to post-1997 inclusion of domestic terrorist events) in data on victims/event, on victims per adverse event, or on the fatal fraction of adverse events (Figures 5-7, 10), events during 1968-2004 that yielded $\geq 1$ victim (casualty or death) were pooled for the purpose of extreme-value analysis. Generalized Pareto (GP) models appear to describe extreme-value patterns exhibited in Israeli and OtherRegion data on victims per adverse or lethal event reasonably well (Figure 16). Corresponding model parameter estimates and confidence limits are listed in Table 4 (rows 1-4). The fits obtained for Israeli vs. combined non-Israeli regions differ markedly. In view of similarly marked differences in the fatality and relative frequency of gun- vs. bomb-related adverse or fatal incidents in Israel vs. all other regions combined (Figures 11-12), additional weaponspecific GP-model fits shown in Figure 17 were obtained, for which corresponding parameter estimates and confidence limits are listed in Table 3 (rows 5-12). These additional fits similarly characterize the extreme-value data on victims/event reasonably well, with shape parameter $(\square$ values estimated to be either $\sim 0$ (notably, for all fits involving gun- or bomb-related deaths) or significantly $<0$ (most notably for fits involving gun- or bomb-related casualties in Israel), and in no case significantly $>0$. The weapon-specific fits obtained for Israeli vs. combined non-Israeli regions clearly differ markedly for data on bomb-related deaths and casualties and on gun-related casualties. 


\section{Discussion}

A number of statistically significant temporal trends were identified in RAND-MIPT data on international terrorist events from 1968-1997, including trends for adverse events, the adverse fraction of all events, total victims, victims/event, and unweighted fatal fraction of adverse events. Most of these significant trends pertain also to the larger period 1968-2004, which includes the post-1997 period during which domestic events have been included in the RANDMIPT database. An increased lethality trend, observed in many previous studies on terrorism (Frey and Leuchinger, 2003), has been attributed to the increasing proportion of fundamentalist religion-based terrorist groups seeking mass casualties of innocent people to make their cause widely known, in contrast to leftist/nationalist terrorists who prefer to persuade hearts and minds toward revolution by avoiding the death or injury of people not directly connected with an existing political and economic regime (Hoffman 1997, 1998; Juergensmeyer, 1997).

RAND-MIPT data analyzed clearly indicate a persistent, relatively very high mortality and morbidity burden faced by Israel from terrorism during 1968-2004, compared to all other regions combined. Lifetime (70-year) equivalent risks of casualty estimated in this study to be between $10^{-3}$ and $10^{-2}$, and corresponding mortality risks between $10^{-4}$ and $10^{-3}$, approach or exceed corresponding occupational hazard levels for industrial workers in economically advanced nations. In contrast, corresponding lifetime casualty risks between $10^{-6}$ and $10^{-4}$ and mortality risks between $10^{-6}$ and $2 \square 10^{-5}$ experienced in non-Near-Eastern regions are risk levels that, in a public health context, are typically considered de minimis. The RAND-MIPT data do, however, exhibit the significant upward temporal trend noted in log-casualty rates for most of the world, that have increased by about two orders of magnitude over 40 years (Figure 14). Any public health significance of this trend can only be assessed in the broader context of lifetime risks of 
casualty from all forms of organized human violence, accounting for changes over time in how such violence has been defined and classified (e.g., as war, civil war, revolution, crime or “terrorism").

In contrast to the relatively high risk burden faced by Israel during 1968-2004, RANDMIPT data for this period also clearly indicate a persistent, relatively low fatal fraction of terrorism-related casualties (particularly for gun-related casualties) in Israel compared to all other regions combined. A key factor contributing to lower $F_{\text {fat }}$ values in Israel compared to other regions is the very effective, integrated system of world-renowned and remarkably successful emergency medical research and services developed over many decades in Israel, in part due to its adaptive response to casualties generated by persistent terrorism there. In addition to its integrated delivery system, emergency medical services in Israel have benefited from related highly effective technologies developed in that country over the last decade, such as the emergency "Israeli bandage" that since 2002 has become standard equipment in many U.S. military and law-enforcement organizations, due to its ability to provide easily administered, immediate hemorrhage control, and so prevent death from shock before other treatment is possible (Blackburn, 2005). Israeli emergency medical system has increased survival among all (terror- and non-terror-related) severe trauma patients over time, though experience treating terror-related trauma there has shown these injuries to involve greater risk of death, greater involvement of younger victims, more serious and extensive burns, more penetrating injuries, greater vascular damage, greater requirement for surgery, and greater risk of very serious longterm disability and rehabilitation than in cases unrelated to terrorism (Aharonson-Daniel et al., 2003; Paleg and Aharonson-Daniel, 2004; Paleg et al., 2003, 2004). While the Israeli emergency medical system has been shown to be increasingly effective in recent years at reducing mortality 
associated with terror-related injuries, relatively low $F_{\text {fat }}$ values for Israel compared to all other regions combined have shown no evidence of a temporal trend over the last four decades (Figure 10). Thus, the primary factor explaining this difference must lie in the combination of a greater fraction of bomb- vs. gun-related casualties, together with lesser $F_{\text {fat }}$ values for both bombs and guns, in Israel compared to all other regions combined.

Marked heterogeneity in event harmfulness exhibited in RAND-MIPT (Figure 13) clearly indicates the relative importance of extremely harmful events in contributing to victim totals, and so highlights the potential importance of better understanding extreme-value behavior in victim/event rates associated with terrorism. Regularity in weapon-specific extreme-value patterns for victims/event appear to be described well by Pareto (or nearly Pareto) distributions (i.e., generalized Pareto distributions with shape parameters equal or nearly equal to zero) for six of eight region/weapon/endpoint combinations examined, and to be described reasonably well by generalized Pareto distributions with a substantially negative shape parameter in the cases of gun and bomb-related casualties in Israel (Table 4, Figure 17).

The regularity of extreme-value behavior in RAND-MIPT victims/event data support their interpretation as meaningful estimates with statistical properties that indicate common underlying mechanisms - mechanisms that have outcomes as predictable as those of other physical phenomena to which extreme-value analysis is applied routinely, such as rainfall, wind speeds, earthquakes sea levels and the like. The fact that GP-model fits obtained in this study reflect shape parameters that are approximately zero or are negative, but not substantially positive, is quite interesting. Just this type of constraint on extreme-value behavior is predicted generally for complex systems in which failure tolerances have been optimized to limit predictable losses conditional on resource constraints and on specified levels of risk aversion. 
Complex systems that trade off resource allocations and losses to achieve highly optimized tolerance (HOT) using a risk-neutral strategy are robust to common perturbations but susceptible to rare ones, and so exhibit "fragile" extreme-loss-event distributions characterized by "heavy" upper-tail with likelihoods that decrease at an exponential (first-order) rate proportional to the value (or logarithm) of the corresponding cost or loss to the system (Doyle and Carlson, 2000; Zhou and Carlson, 2000; Carlson and Doyle, 2002). HOT models thus exhibit just the kind of extreme-value behavior that is predicted by a Pareto model (i.e., a GP model with a shape parameter equal to zero). Risk aversion expressed in systems that are more intolerant of high losses by constraining values (or log) of any extreme loss to increase only as a sub-linear function of its negative log-likelihood (Newman et al., 2002). Systems that optimize resources to constrain losses in a risk averse manner thus have the same extreme-value behavior as GP models with a negative shape parameter.

Regularities exhibited by extreme values of victim/event rates within RAND-MIPT data indicate patterns that appear to be a potentially very reliable basis for designing efficient countermeasure, insurance or regulatory strategies to limit and manage the consequences of acts of terrorism. Methods now being explored to manage terrorism risks through, for example, insurance mechanisms (e.g., Kunreuther, 2002) do an address how such approaches might best take advantage of relevant extreme-value data. Results from the present study suggest that new approaches that account for historically based empirical data on extreme victims/event rates are feasible and may be superior to current methods that rely on less relevant information.

Internal consistencies as well as statistical strengths of patterns and trends identified in this study certainly call into question the blanket admonition by MIPT (2004c) that its data "should not be used as a tool for any sort of analysis, predictive or otherwise." On the contrary, results 
from the present study raise the question of whether earlier public release and broader analysis of the emerging data might better have assisted the design of more effective strategies to manage terror-related risks. Of course, any conclusions based on apparent patterns and trends identified in this study clearly are conditional on the reliability of RAND-MIPT data analyzed. These data have many potential sources of bias or error that merit careful consideration, including (by no means exhaustively): ambiguity or inconsistency in the definition of events included vs. excluded from the data base; records that may be missing or incomplete due to ongoing data base management; data missing due to lack of records or media coverage; and perhaps most importantly, primary reliance on unconfirmed or potentially biased or potentially inaccurate reports by local news media. It is reasonable to assume that large, overall patterns and trends observed in the present study are not artifacts due to isolated errors or omissions concerning small numbers of particular incident records. The potential impact of any pervasive systematic biases are more difficult to assess.

Insofar as initial news-media reports of terrorist events appear to have been the primary source of input to the RAND-MIPT data base, a key source of potential bias reflected in this data base would be the fact that such reports may reflect inaccurate initial "guess-timates" of total injuries and/or deaths by local reporters, or even politically motivated distortion of true victim counts in regions that lack independent news media. Corrections or refinements to initial news accounts may or may not appear in subsequent media reports, and if any do appear, it is not clear what if any systematic RAND-MIPT efforts are made to update previous records. Evidence for non-random bias in RAND-MIPT data appears in Figure 8, in which each cumulative distribution shown has a substantial jump in relative frequency (ordinate) at corresponding $F_{\text {fat }}$ (abscissa) values equal precisely to one third and to one half. These jumps clearly reflect 
incorporation into RAND-MIPT data of crude initial estimates of the fatal fraction of casualties estimated for each event, rather than estimates based on confirmed hospital records or other more reliable data sources.

Hospital records are available in the case of Israel, which administers an Israel National Trauma Registry of all hospitalizations for physical trauma at nine Israeli trauma centers (including six level-1 centers) that are part of a tertiary care and referral system that receive the majority of severe or complicated cases of physical injury throughout Israel; this Registry tracks, among other things, in-hospital deaths and whether each incident is related to terrorism (Aharonson-Daniel et al., 2003). Between November 1, 2000, and June 30, 2003, this Registry recorded 1,661 terror-related injuries resulting in 100 in-hospital deaths (Paleg and AharonsonDaniel, 2004). Over the same period in Israel, the RAND-MIPT data include a total of 3,353 casualties including 2,861 injuries and 494 deaths. One source of these discrepancies may be that initial casualty estimates made by Israeli (and perhaps most local) media and entered into RAND-MIPT data tend to overestimate actual casualties. It is also likely that RAND-MIPT data include estimates of people not covered in the National Trauma Registry, who include those with relatively minor injuries that did not require hospitalization, deaths at the scene of events or on hospital arrival, and/or outpatient deaths that occurred subsequent to hospitalization (AharonsonDaniel et al., 2003). In cases where accurate records of terrorism-related casualties can be reconstructed, systematic comparison of such information with RAND-MIPT data would help clarify the source of any discrepancies and perhaps also the extent to which these may pertain to other parts of the RAND-MIPT data base.

Despite potential data limitations, a number of patterns and trends were identified in this study concerning mortality and morbidity from terror-related events worldwide. Some of these 
appear to have predictive value that may be used to improve current or planned systems for preventing and managing consequences of terror-related events.

Acknowledgements - This work was performed under auspices of the U.S. Department of Energy by University of California, Lawrence Livermore National Laboratory (LLNL) under Contract W-7405-Eng-48, with support from the LLNL Risk and Response Management Program. We are grateful for insights and suggestions provided by Steven E. James pertaining to this work.

\section{References}

Aharonson-Daniel, L, Y Waisman, YL Dannon, and K Peleg. 2003. Epidemiology of terrorrelated versus non-terror-related traumatic injury in children. Pediatrics 112 (4), e280.

Blackburn, N. 2005. Israeli innovative bandages saving American lives in Iraq. Israel21c (www.israel21c.org) Jan. 9, 2005.

Bogen, KT. 2002. RiskQ 4.2: An Interactive Approach to Probability, Uncertainty and Statistics for use with Mathematica ${ }^{\circledR}$. UCRL-MA-110232 Rev. 3. Lawrence Livermore National Laboratory, Livermore, CA.

Carlson, JM, and J Doyle. 2002. Complexity and robustness. Proc. Natl. Acad. Sci. USA (PNAS) 99, 2538-2545.

Snedecor, GW, and WG Cochran. 1989. Statistical Methods. 8th ed. Iowa State University Press, Ames, IA.

Coles, S 2001. An Introduction to Statistical Modeling of Extreme Values. Springer-Verlag, London, UK. 
Coles, S, and L Pericchi. 2003. Anticipating catastrophes through extreme value modelling. $J$. Roy. Statist. Soc. Series C (Appl. Statist.) 52, 405-416.

Congleton, R. 2002. Terrorism, interest-group politics, and public policy: curtailing criminal modes of political speech. Independ. Rev. 7(1), 28 p. http://www.independent.org/publications/tir/article.asp?issueID=16\&articleID=118 .

Doyle, J and JM Carlson. 2000. Power laws, highly optimized tolerance, and generalized source coding. Phys. Rev. Lett. 84, 5656-5659.

Ellis, JO. 2004. MIPT: Sharing terrorism information resources. Intelligence and Security Informatics, Proceedings Lecture Notes in Computer Science 3073, 520-525.

Frey, BS, and S Leuchinger. 2003. Measuring terrorism. Institute for Empirical Research in Economics University of Zurich Working Paper Series (ISSN 1424-0459), Working Paper No. 171, October 2003.

Hoffman, B. 1997. The confluence of international and domestic trends in terrorism. Terrorism and Political Violence 9, 1-15.

Hoffman, B. 1998. Inside Terrorism. Colombia University Press. New York, NY.

Juergensmeyer, M. 1997. Terror mandated by God. Terrorism and Political Violence 9, 16-23.

Kendall, M, and A Stuart. 1979. The Advanced Theory of Statistics, Vol. 2: Inference and Relationship. 4th ed. MacMillan Publishing Co., NY, pp. 159-60.

Kunreuther, H. 2002. The role of insurance in managing extreme events: implications for terrorism coverage. Risk Anal. 22, 427-437.

Memorial Institute for the Prevention of Terrorism (MIPT). 2004a. MIPT Terrorism Knowledge Base: A Comprehensive Databank of Terrorist Incidents and Organizations. Incident data updated November 24, 2004. http://www.tkb.org/Home.jsp.

Memorial Institute for the Prevention of Terrorism (MIPT). 2004b. Understanding the terrorism database. MIPT Quart. Bull. ${ }^{\text {st }}$ quarter 2002 (www.mipt.org/MIPT-Bulletins.asp), 4-6. 
Memorial Institute for the Prevention of Terrorism (MIPT). 2004c. RAND Terrorism Chronology 1968-1997 and RAND ${ }^{\circledR}$-MIPT Terrorism Incident database (1998-Present). Incident data updated November 24, 2004. http://www.tkb.org/RandSummary.jsp.

Newman, MEJ, M Girvan, and JD Farmer. 2002. Optimal design, robustness, and risk aversion. Phys. Rev. Lett. 89, 028301-1 - 028301-4.

Peleg, K, L Aharonson-Daniel, M Michael, and SC Shapira. 2004. Patterns of injury in hospitalized terrorist victims. Am. J. Emergency Med. 21, 258-262.

Peleg, K, L Aharonson-Daniel, M Stein, Y Kluger, M Michaelson, A Rivkind, and V Boyko. 2004. Increased survival among severe trauma patients. Arch. Surg. 139, 1231-1236.

Peleg, K, and L Aharonson-Daniel. 2004. Epidemiology of terror related injuries. Abstract 4199.0. American Public Health Association (APHA), $132^{\text {nd }}$ Annual Meeting ("Public Health and the Environment"), Washington, DC, Nov. 6-10, 2004.

U.S. Bureau of the Census (USBC). International Data Base. 2004. Total Midyear Population for the World: 1950-2050. Data updated 9-30-2004. year Population for the World: 1950-2050. http://www.census.gov/ipc/www/worldpop.html.

Wolfram S. 1999. Mathematica Book, 4th ed. Cambridge University Press: Cambridge, UK.

Wright, S.P. 1992. Adjusted p-values for simultaneous inference. Biometrics 48, 1005-1013.

Zhou, T, and JM Carlson. 2000. Dynamics and changing environments in highly optimized tolerance. Phys. Rev. E 62, 3197-3204. 


\section{Tables}

Table 1. Summary of RAND-MITP data on terrorist events, by period. ${ }^{a}$

\begin{tabular}{|ccccccc|}
\hline & $\begin{array}{c}\text { Events } \\
\text { Period }^{a}\end{array}$ & $\begin{array}{c}\text { Adverse } \\
\text { events } \\
(n)\end{array}$ & $\begin{array}{c}F_{\text {adv }}=n / e \\
(\%)\end{array}$ & $\begin{array}{c}\text { Injuries }^{b} \\
(c-m)\end{array}$ & $\begin{array}{c}\text { Deaths } \\
(m)\end{array}$ & $\begin{array}{c}F_{\text {fat }}=m / c \\
(\%)\end{array}$ \\
\hline 1970 & 760 & 135 & 17.8 & 665 & 385 & 36.7 \\
1975 & 1,201 & 319 & 26.6 & 1,827 & 855 & 31.9 \\
1980 & 1,390 & 480 & 34.5 & 3,509 & 1,193 & 25.4 \\
1985 & 1,831 & 629 & 34.4 & 5,029 & 2,308 & 31.5 \\
1990 & 1,747 & 548 & 31.4 & 3,442 & 1,713 & 33.2 \\
1995 & 1,301 & 545 & 41.9 & 13,665 & 2,003 & 12.8 \\
$2000^{a}$ & 7,948 & 3,030 & 38.1 & 23,642 & 11,154 & 32.1 \\
$2005^{a}$ & 9,125 & $4,287.5$ & 47.0 & $35,397.5$ & $14,492.5$ & 29.0 \\
\hline All 40 yrs & 25,303 & $9,973.5$ & 39.4 & $87,176.5$ & $34,103.5$ & 28.1 \\
\hline
\end{tabular}

${ }^{a}$ Periods are named by midpoint of a corresponding 5-year interval, starting with $1968-1972$ and ending with 2003 - 2007. Values listed for 2000 and 2005 include "domestic" terrorism events, whereas data for earlier periods do not. Projected totals listed for $2003-2007$ were estimated by linear extrapolation from data reported for $2003-$ 2004.

${ }^{b}$ Casualties $(c)$ here denotes the sum of the number $(m)$ of persons killed plus the number $(c-m)$ who are non-fatally injured. 
Table 2. Events and consequences in all regions combined, by weapon type. ${ }^{a}$

\begin{tabular}{|lcccccc|}
\hline & $\begin{array}{c}\text { \% of all } \\
\text { events, } \\
n / E\end{array}$ & $\begin{array}{c}\text { \% of all } \\
\text { adverse } \\
\text { events, } \\
n / N\end{array}$ & $\begin{array}{c}\text { \% of all } \\
\text { casualties, } \\
c / \square c\end{array}$ & $\begin{array}{c}\text { \% of all } \\
\text { deaths, } \\
m / \square m \\
\text { Weapon }{ }^{a}\end{array}$ & $\begin{array}{c}\text { Unweighted } \\
\text { fatal fraction, } \\
F_{\text {fat }}=\overline{m / n}\end{array}$ & $\begin{array}{c}\text { Weighted } \\
\text { fatal fraction, } \\
F_{\text {fat }}=\square m / \square n \\
(\%)\end{array}$ \\
\hline Bombs & 53.4 & 41.8 & 66.5 & 48.1 & 24.2 & 20.1 \\
Guns & 19.9 & 36.4 & 12.5 & 22.9 & 65.5 & 51.2 \\
Sharps & 1.3 & 3.3 & 0.6 & 1.2 & 64.4 & 53.9 \\
R-Bombs & 1.9 & 2.4 & 4.4 & 3.2 & 21.2 & 20.0 \\
Fire & 9.8 & 1.6 & 2.6 & 2.7 & 30.5 & 29.4 \\
Chemical & 0.2 & 0.3 & 5.8 & 0.1 & 31.9 & 0.4 \\
Biological & 0.08 & 0.1 & 0.02 & 0.02 & 38.3 & 35.3 \\
Other & 13.3 & 14.1 & 7.7 & 21.7 & 78.2 & 78.9 \\
\hline Tot. or Ave. ${ }^{b}$ & 100.0 & 100.0 & 100.0 & 100.0 & 48.2 & 27.8 \\
\hline
\end{tabular}

${ }^{a}$ Potencies are calculated per adverse event, based on MIPT-RAND data for 1968-2004, involving a total of $\mathrm{E}=$ 19,828 events, $N=7,401$ adverse events, 91,346 casualties and 25,408 deaths. Sharps $=$ knives and other bladed weapons, R-Bombs = remote-control bombs, Chemical = chemical agent(s), Biological = biological agent(s); "Other" includes unknown or unspecified. See Table 1 for definition of other notation. See text concerning temporal trends.

${ }^{b}$ In this row, totals are listed in columns 2-5 and $c$-weighted average values are listed in columns 6-7. 
Table 3. Events and consequences in Israel, by weapon type. ${ }^{a}$

\begin{tabular}{|lcccccc|}
\hline & $\begin{array}{c}\text { \% of all } \\
\text { events, } \\
n / E\end{array}$ & $\begin{array}{c}\text { \% of all } \\
\text { adverse } \\
\text { events, } \\
n / N\end{array}$ & $\begin{array}{c}\text { \% of all } \\
\text { casualties, } \\
c / \square c\end{array}$ & $\begin{array}{c}\text { \% of all } \\
\text { deaths, } \\
m / \square m \\
\text { Weapon }^{a}\end{array}$ & $\begin{array}{c}\text { Unweighted } \\
\text { fatal fraction, } \\
F_{\text {fat }}=\overline{m / n}\end{array}$ & $\begin{array}{c}\text { Weighted } \\
\text { fatal fraction, } \\
F_{\text {fat }}=\square m / \square n \\
(\%)\end{array}$ \\
\hline Bombs & 62.8 & 59.7 & 84.8 & 77.1 & 16.8 & 14.5 \\
Guns & 13.6 & 15.4 & 8.5 & 9.3 & 35.1 & 17.5 \\
Sharps & 8.2 & 13.9 & 1.5 & 3.3 & 41.2 & 33.1 \\
R-Bombs & 1.7 & 0.9 & $<0.1$ & 0 & 0 & 0 \\
Fire & 5.7 & 0.9 & 0.2 & 0 & 0 & 0 \\
Chemical & 0 & 0 & 0 & 0 & 0 & 0 \\
Biological & 0 & 0 & 0 & 0 & 0 & 0 \\
Other & 8.0 & 9.2 & 5.9 & 10.3 & 49.8 & 33.2 \\
\hline Tot. or Ave. ${ }^{b}$ & 100.0 & 100.0 & 100.0 & 100.0 & 25.8 & 15.9 \\
\hline
\end{tabular}

${ }^{a}$ Potencies are calculated per adverse event, based on MIPT-RAND data for 1968-2004, involving a total of $\mathrm{E}=785$ events, $N=447$ adverse events, 8,374 casualties and 1,334 deaths. See Table 2, note $a$.

${ }^{b}$ In this row, totals are listed in columns $2-5$ and $c$-weighted average values are listed in columns 6-7. 
Table 4. Generalized Pareto model fits to MIPT-RAND victims/event data. ${ }^{a}$

\begin{tabular}{|c|c|c|c|c|c|c|}
\hline $\operatorname{Region}^{a}$ & Endpoint $^{b}$ & Weapon $^{b}$ & $u$ & $\begin{array}{c}\nearrow \\
(95 \% \mathrm{CL}) \\
\end{array}$ & $\begin{array}{c}\Gamma \\
(95 \% \mathrm{CL})^{a}\end{array}$ & $\mathrm{p}_{\square \neq 0}$ \\
\hline Rest & Casualty & All & 5 & $\begin{array}{c}0.532 \\
(0.502,0.563)\end{array}$ & $\begin{array}{c}-0.108 \\
(-0.147,-0.070)\end{array}$ & $4 \square 10^{-6}$ \\
\hline Israel & Casualty & All & 5 & $\begin{array}{c}1.03 \\
(0.890,1.18)\end{array}$ & $\begin{array}{c}-0.632 \\
(-0.728,-0.536)\end{array}$ & $\sim 0$ \\
\hline Rest & Death & All & 20 & $\begin{array}{c}0.365 \\
(0.308,0.421)\end{array}$ & 0 & 0.59 \\
\hline Israel & Death & All & 10 & $\begin{array}{c}0.241 \\
(0.166,0.316) \\
\end{array}$ & 0 & 0.11 \\
\hline Rest & Casualty & Bombs & 20 & $\begin{array}{c}0.429 \\
(0.384,0.474)\end{array}$ & $\begin{array}{c}-0.112 \\
(-0.176,-0.0479)\end{array}$ & 0.0052 \\
\hline Israel & Casualty & Bombs & 5 & $\begin{array}{c}1.12 \\
(0.946,1.29)\end{array}$ & $\begin{array}{c}-0.685 \\
(0.946,1.29)\end{array}$ & $\sim 0$ \\
\hline Rest & Casualty & Guns & 20 & $\begin{array}{c}0.353 \\
(0.256,0.450)\end{array}$ & 0 & 0.32 \\
\hline Israel & Casualty & Guns & 5 & $\begin{array}{c}1.34 \\
(0.668,2.02)\end{array}$ & $\begin{array}{c}-0.937 \\
(-1.43,-0.443)\end{array}$ & 0.0055 \\
\hline Rest & Deaths & Bombs & 10 & $\begin{array}{c}0.373 \\
(0.325,0.420)\end{array}$ & 0 & 0.47 \\
\hline Israel & Deaths & Bombs & 10 & $\begin{array}{c}0.232 \\
(0.156,0.308)\end{array}$ & 0 & 0.16 \\
\hline Rest & Deaths & Guns & 20 & $\begin{array}{c}0.340 \\
(0.207,0.474)\end{array}$ & 0 & 0.62 \\
\hline Israel & Deaths & Guns & 5 & $\begin{array}{c}0.155 \\
(0.0310,0.279)\end{array}$ & 0 & 0.034 \\
\hline
\end{tabular}

${ }^{a}$ Model fits were performed conditional on the specified value of the Generalized Pareto threshold parameter $u$, and if $\mathrm{p}_{e=0}>0.01$ also on $e=0$ (see Methods). Rest $=$ all other regions besides Israel. A $\mathrm{p}_{e=0}$ value $<10^{-15}$ is indicated by $\sim 0$.

${ }^{b}$ Events included were those during 1968-2004 that resulted in $\geq 1$ case of the specified endpoint. Bombs here includes remote-controlled bombs. 


\section{Figures and Legends}
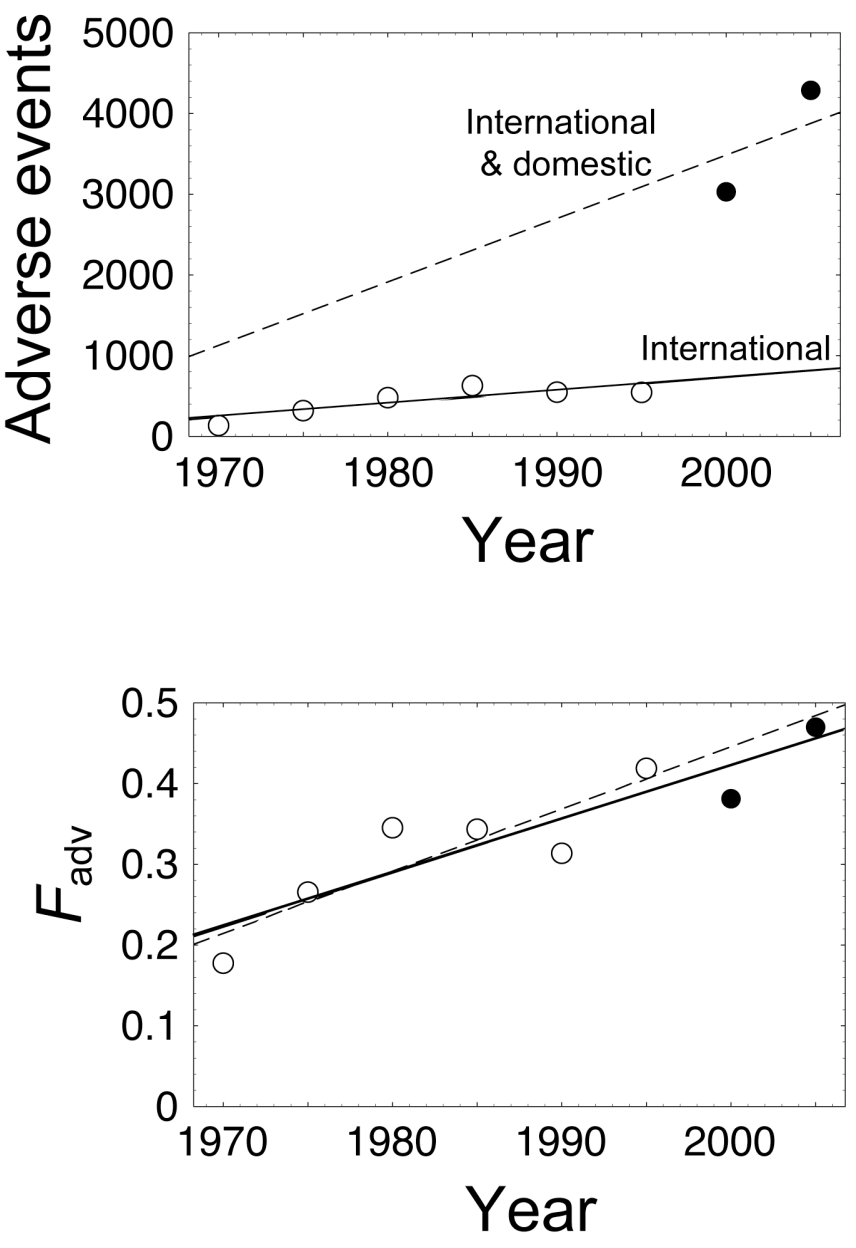

Figure 1. Number of adverse events (AE) during 5 -y periods starting in 1968, including only "international" terrorist events (open points) prior to 1998 , but thereafter include "domestic (intranational) and international" events (solid points). AE during 2005-07 were estimated by linear extrapolation from 2003-04 data. The pre-1998 data exhibit a significant positive trend (solid line, $\left.\mathrm{R}^{2}=0.71, \mathrm{p}=0.035\right)$. A linear fit (dashed line) is shown for pre-1998 data conditional on $\mathrm{X}_{0}(\sim 1956)$ estimated from pre-1998 data; the post-1997 slope is $\sim 4.8$ times greater than the I-only slope.

Figure 2. The adverse fraction $\left(F_{\text {adv }}\right)$ of all events (i.e., fraction of all events that caused one or more casualties) during 5-y periods starting in 1968. Solid points highlight post-1997 values. The linear fit to all data points (solid line, $\mathrm{R}^{2}=0.82, \mathrm{p}$ $=0.0019)$ is consistent ( $p>0.56$, by 2 -point F-test for outliers) with that obtained to data excluding post-1997 values (dashed line, $\mathrm{R}^{2}=0.77, \mathrm{p}=$ 0.022 ). The former and latter fits correspond to an increase in $F_{\text {adv }}$ of $6.7 \%$ and $7.7 \%$ per decade, respectively.

Figure 3. Fraction $\left(F_{\text {adv }}\right)$ of all events that were adverse during 5-y intervals starting in 1968, by geographic region within three regional groups: Israel $(\square)$, Group $1(\bullet=$ Africa, Latin America, Near East [excluding Israel and the Occupied Territories], and South Asia), and Group 2 ( $\mathrm{O}=$ all other regions). Adjusting for 3 independent tests, Group 1 data have a significant positive trend (long-dashed line, $\mathrm{p}_{\text {adj }}=0.00055$ ), while those for Israel (mean $=0.60$, upper short-dashed line) and Group 2 (mean $=0.27$, lower short-dashed

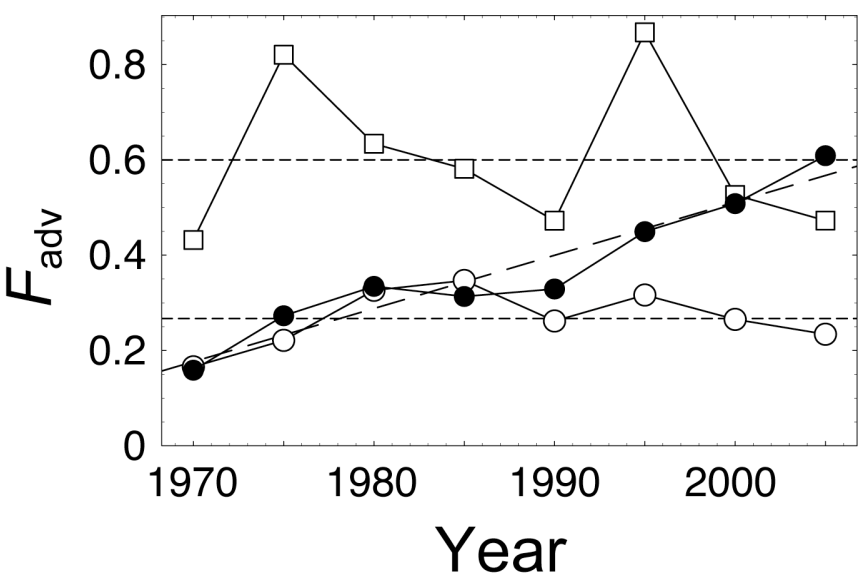
line) do not $\left(\mathrm{p}_{\mathrm{adj}}>0.80\right)$. The same general pattern pertains to pre-1998 data within these groups. 


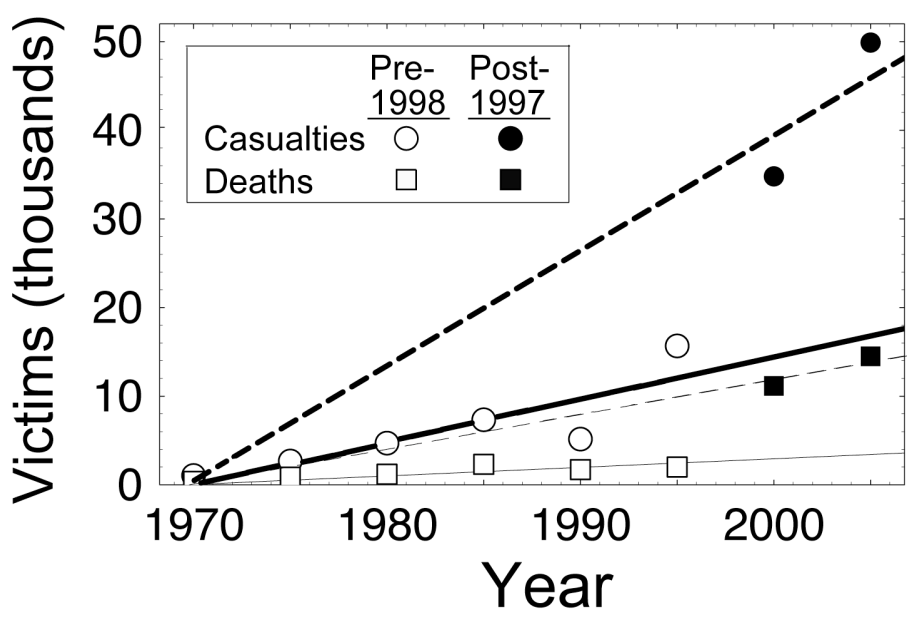

Figure 4. Victims of terrorism during 5-y periods starting in 1968. Linear fits to pre1998 data on casualties (bold line, $\mathrm{R}^{2}=0.74$, $\mathrm{p}=0.028$ ) and deaths (thin line, $\mathrm{R}^{2}=0.75, \mathrm{p}$ $=0.027$ ) are shown, together with fits (dashed lines) corresponding to the two post1997 data points for each endpoint conditional on the $X_{0}$ estimate $(\sim 1970)$ from pre-1998 data on casualties. The ratios of dashed to corresponding solid slopes shown are $\sim 2.7$ and $\sim 4.1$ for fits to data on casualties and on deaths, respectively.

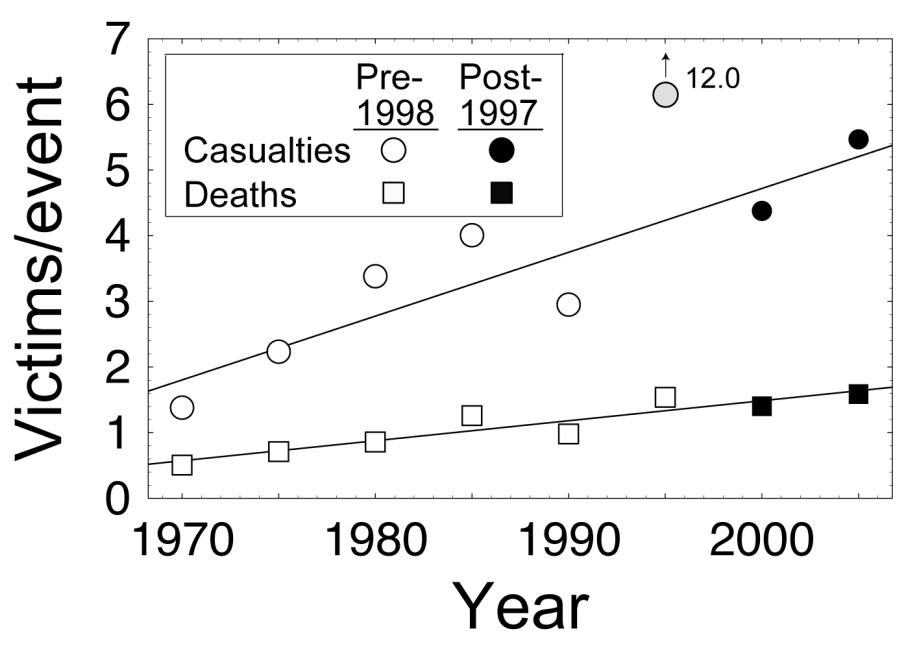

Figure 5. The ratio of total victims to total events during 5-y periods starting in 1968. Corresponding linear fits are shown for all data on deaths (lower line, $\mathrm{R}^{2}=0.87, \mathrm{p}=$ 0.00079 ), and for all data on casualties (upper line, $\left.\mathrm{R}^{2}=0.83, \mathrm{p}=0.0044\right)$ except the point for 1993-97 (shaded grey), which is statistically inconsistent $(\mathrm{p}=0.000091)$ with the linear trend of the other casualty data. The casualty slope is 3.2-fold greater than the mortality slope shown. The positive linear trend for pre-1998 casualties is not statistically significant $(\mathrm{p}=0.072)$, but it is for pre-1998 deaths $\left(R^{2}=0.83, p=0.012\right)$.

Figure 6. The ratio of total victims to total adverse events (AE) during 5-y periods starting in 1968. No temporal trend is evident for either casualties or deaths. Pre1998 data indicate a mean $( \pm$ SEM $)$ of $3.08 \pm$ 0.21 deaths/AE (dashed line) and 12.6 3.3 casualties/event. Casualties/AE data for 1993-97 are not consistent with the corresponding earlier data $(\mathrm{p}=0.00029$ by outlier F-test).

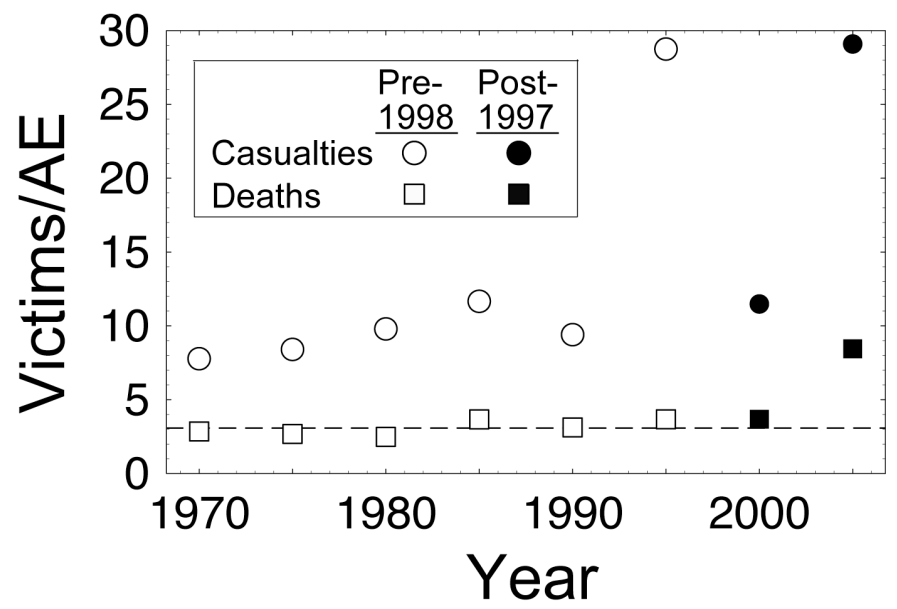


Figure 7. Unweighted vs. casualtyweighted average ratios $F_{\text {fat }}$ of deaths to casualties per adverse event (AE) during 5y periods starting in 1968. (The weighted method was used to obtain values listed in Table 1.) Weighted $F_{\text {fat }}$ values show no trend; they have an overall mean of 0.31 (dashed line) excluding the 1993-97 outlier $(\mathrm{p}=0.0025)$ shown with grey fill, and a mean of 0.29 including that value. In contrast, unweighted $F_{\text {fat }}$ values show an increasing trend that is significant for all points (solid line, $\mathrm{R}^{2}=0.85, \mathrm{p}=0.0010$ ) as well as for only pre-1998 points $\left(\mathrm{R}^{2}=0.70\right.$, $\mathrm{p}=0.037$ ).

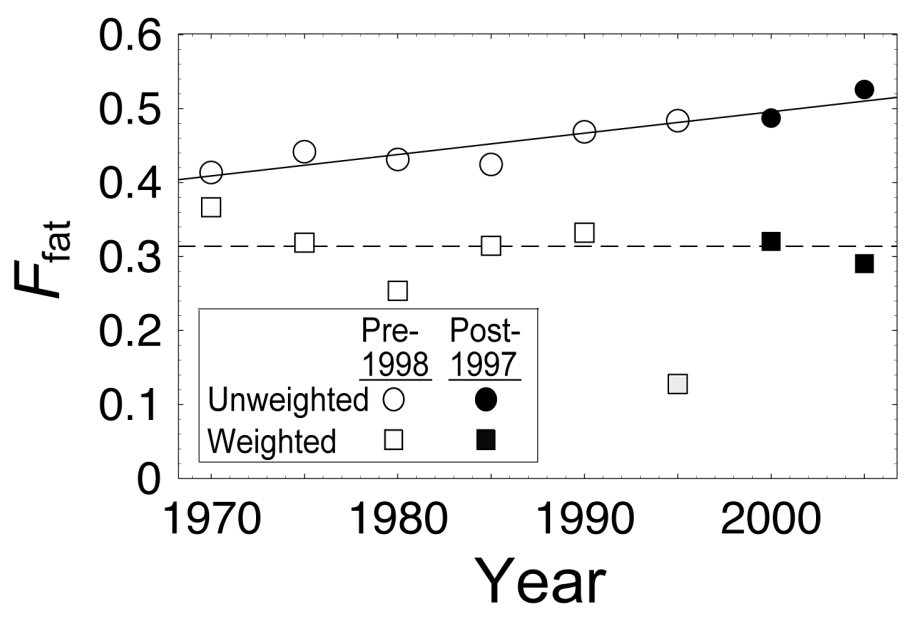

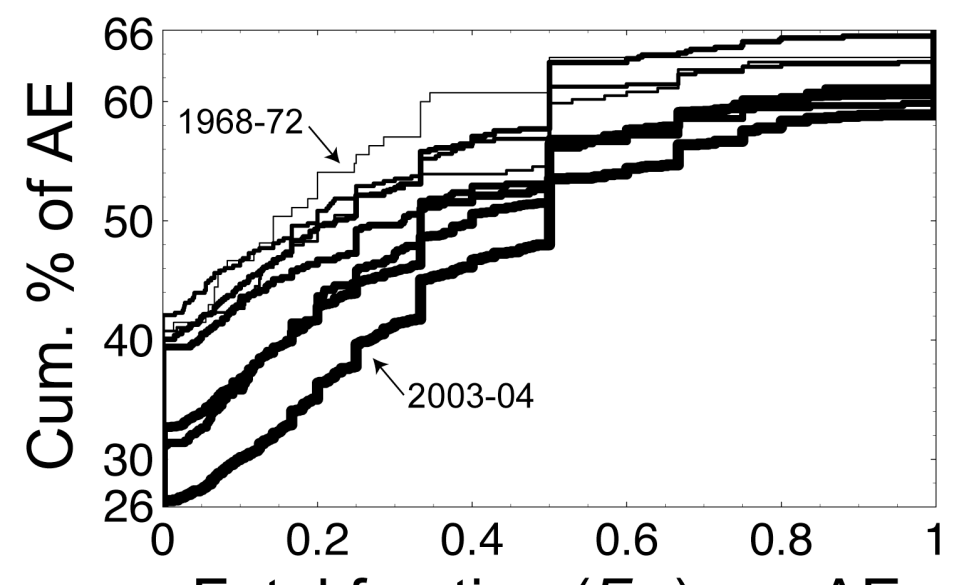
Fatal fraction $\left(F_{\text {fat }}\right)$ per $\mathrm{AE}$
Figure 8. Period-specific cumulative relative-frequency distributions of the unweighted ratio $F_{\text {fat }}$ of deaths to casualties per adverse event (AE), during 8 time periods examined covering 1968-2004, for all regions combined. Distributions for successive periods are shown with solid curves of increasing thickness. Later distributions increasingly shift downward and to the right relative to the starting 1968-72 distribution. 


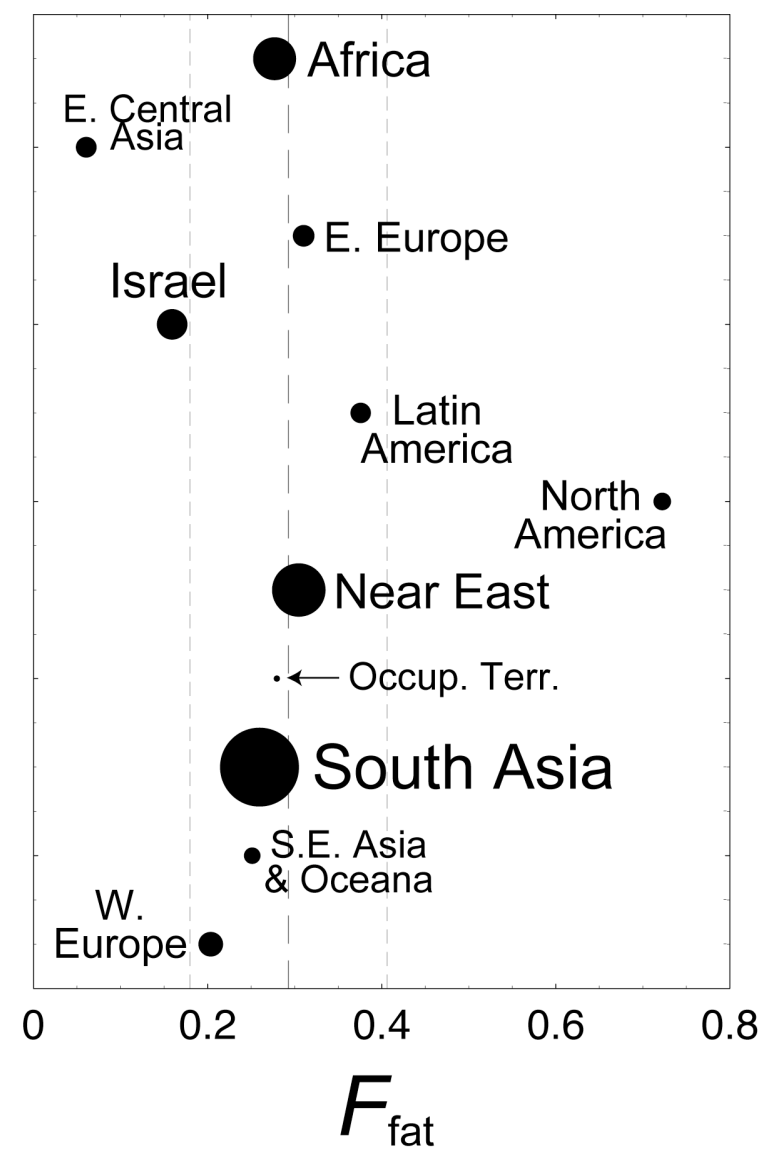

Figure 9. Ratio $F_{\text {fat }}$ (solid points) of total deaths to total casualties summed over all times periods, by geographic region (where Near East excludes Israel and the Occupied Territories). The diameter of data points shown is proportional to corresponding total casualties summed over all time periods. The worldwide $w_{j}$-weighted mean and its corresponding 2-tail 95\% confidence limits for $F_{\text {fat }}$ is 0.292 (vertical long-dashed line) \pm 0.11 (vertical short-dashed lines), where $w_{j}=c_{j} / \square c_{j}$ and $c_{j}=$ casualties over all regions $j$ other than the two outlying regions (North America and E. Central Asia). The deviation of $F_{\text {fat }}$ for the former region from the mean is due primarily to events on Sept. 11, 2001 (for which $F_{\text {fat }}=$ $100 \%$ ), while this deviation and nearly all casualties for E. Central Asia are due primarily to the 1995 Sarin attack in Tokyo, Japan (for which $F_{\text {fat }}<0.3 \%$ ).

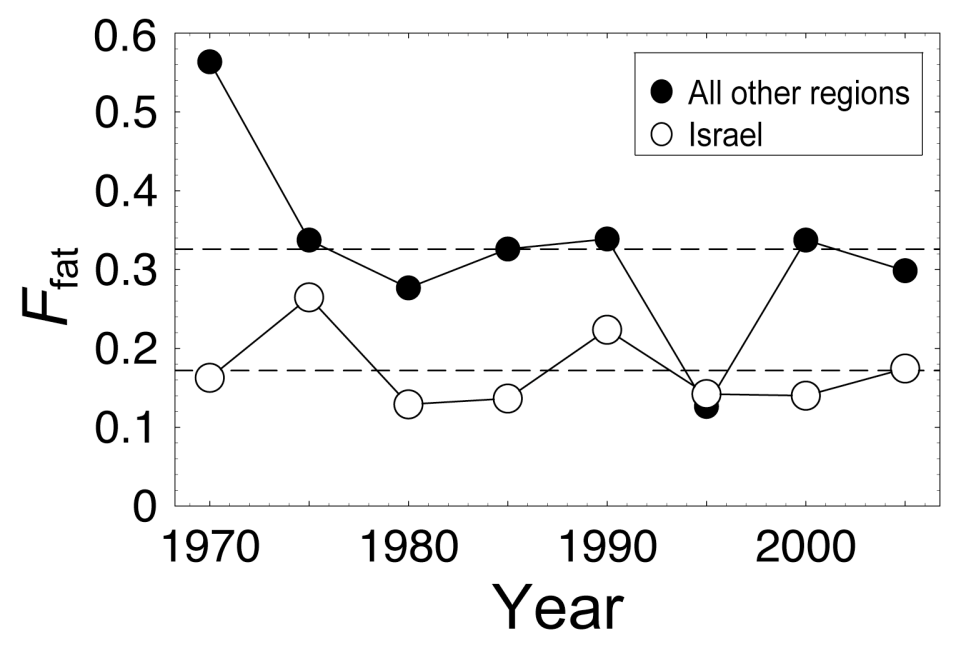

Figure 10. Ratio $F_{\text {fat }}$ of total deaths to total casualties per adverse event during 5-y periods starting in 1968-72, for Israel vs. all other regions combined. The mean value of $F_{\text {fat }}$ for Israel $(0.17$, lower dashed line) over all periods is significantly ( 2 -fold) less ( $\mathrm{p}=$ 0.0078 ) than that of all other regions combined ( 0.33 , upper dashed curve). Likewise, the data for both groups show a common non-significant linear trend, with intercepts that differ significantly $(\mathrm{p}=0.0032$ by ANOCOVA F-test). For this analysis, the 1993-97 point for non-Israel regions was not treated as an outlier. 

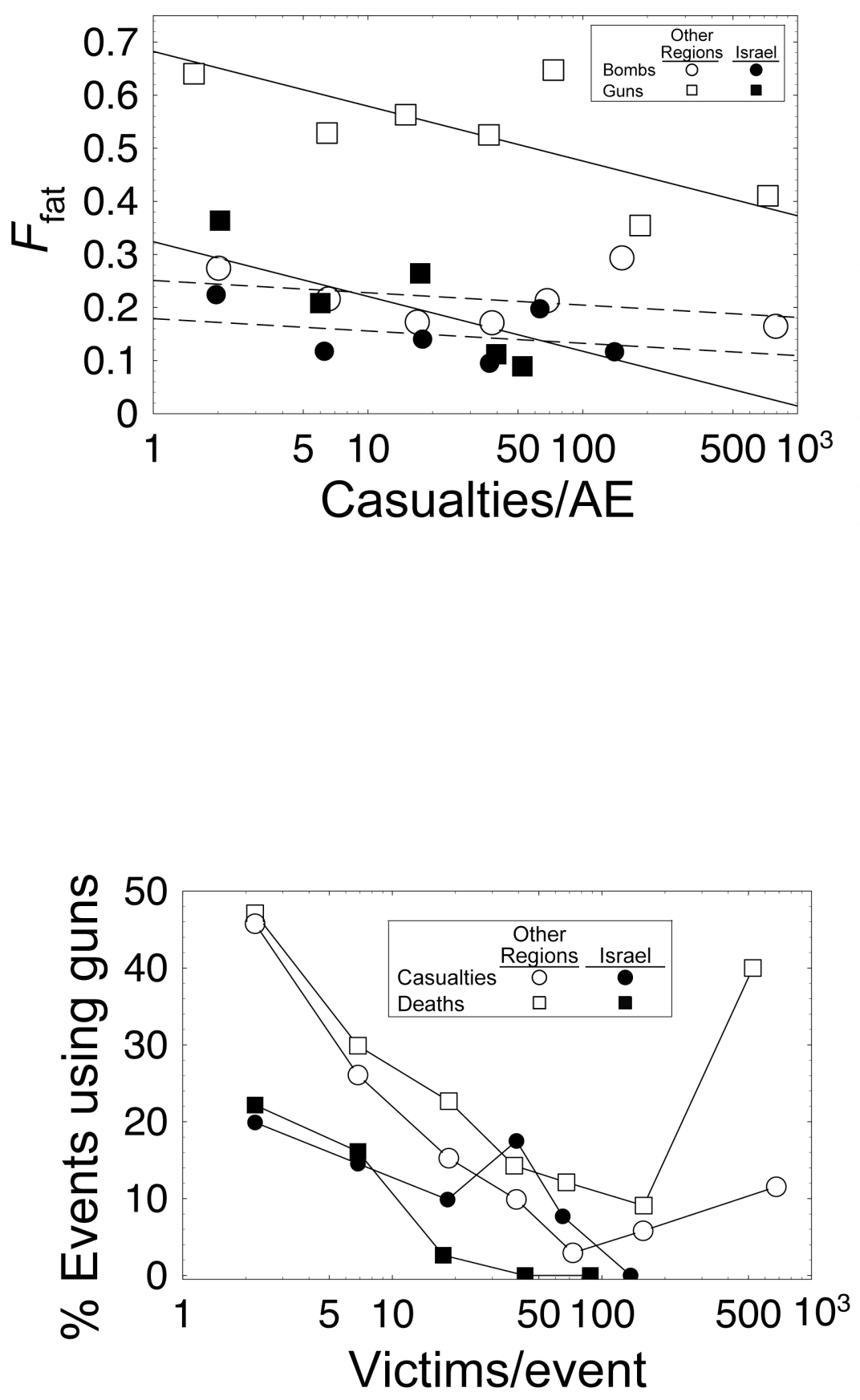

Figure 11. Ratio $F_{\text {fat }}$ of total deaths to total casualties per adverse event (AE) during 1968-2004, vs. mean casualties/AE (within bin ranges), for gun- or bomb-related events that occurred in Israel vs. in all other regions combined. Log-linear trends suggested show (by ANOCOVA) intercepts that are significantly lower for Israel than for other combined regions, for events that involved either bombs (dashed lines, $\mathrm{p}=$ 0.029 ) or guns (solid lines, $\mathrm{p}=$ 0.000038).

Figure 12. Among terrorist events during 1968-2004 that caused $\geq 1$ victim, the percent of events that involved guns is plotted as a function of the total number of victims/event, for events that occurred in Israel vs. in all other regions combined. Israeli gunrelated percents of fatal events are all $\sim 10$ to $20 \%$ lower than are those of other regions; a similar difference for adverse events pertains only to those yielding less than $\sim 10$ victims/event. 

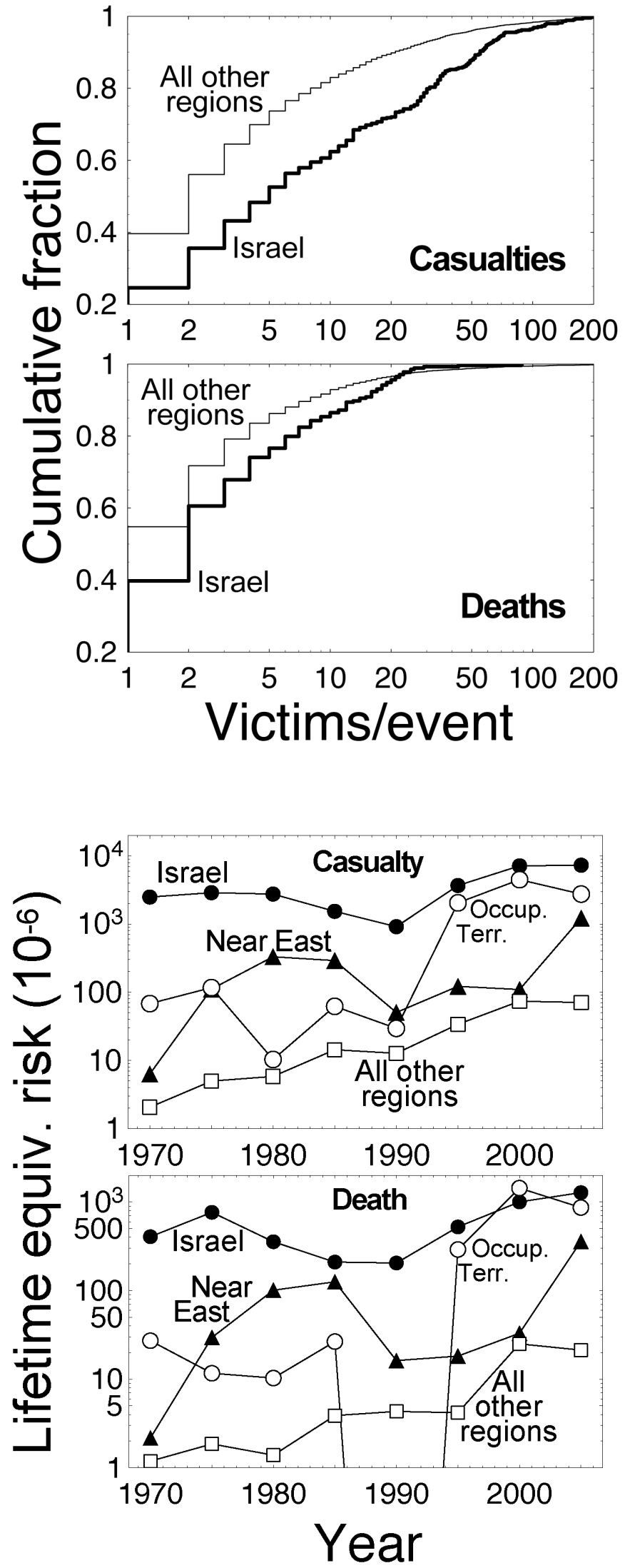

Figure 13. Cumulative relative frequency distributions of victims/event rates for all events causing $\geq 1$ case during 1968-2004, in Israel vs. all other regions combined. (p $\square 0)$ $\left(\mathrm{p}=1.6 \square 10^{-5}\right)$

Figure 14. Equivalent lifetime (70-year) risks of casualty and of death due to terrorism during 5-y periods starting in 1968-72, for Israel, the Occupied Territories, the Near East (excluding Israel and the Occupied Territories), and all other regions combined. None of the region-specific mortality or casualty risks (or log risks) show a significant temporal trend during 1968-97 (prior to the inclusion of domestic events in the MIPTRAND database), after adjusting for multiple trend tests $\left(\mathrm{p}_{\text {adj }}>0.05\right)$, with the exception of non-Near-Eastern (i.e., "All Other") regions, which together do show a significant positive trend in log casualty risks over this period ( $\mathrm{p}_{\text {adj }}$ $=0.0061)$. 


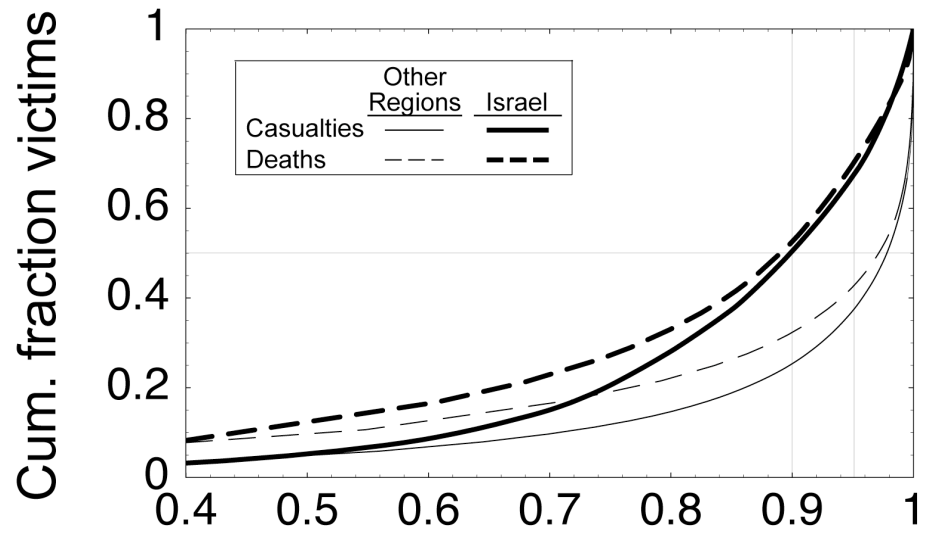

Cum. frac. potency-sorted events
Figure 15. Lorenz curves for total deaths and total casualties due to terrorist events that caused $\geq 1$ victim during 1968-2004, in Israel vs. all other regions combined. Light horizontal/vertical lines highlight $50 \%$ of total victims (horizontal), and events associated with $90^{\text {th }}$ and $95^{\text {th }}$ percentile victims/event rates (vertical). The solid curve at right, for example, shows that $\sim 2 \%$ of all adverse events outside Israel caused $~ 50 \%$ of all casualties in those areas.

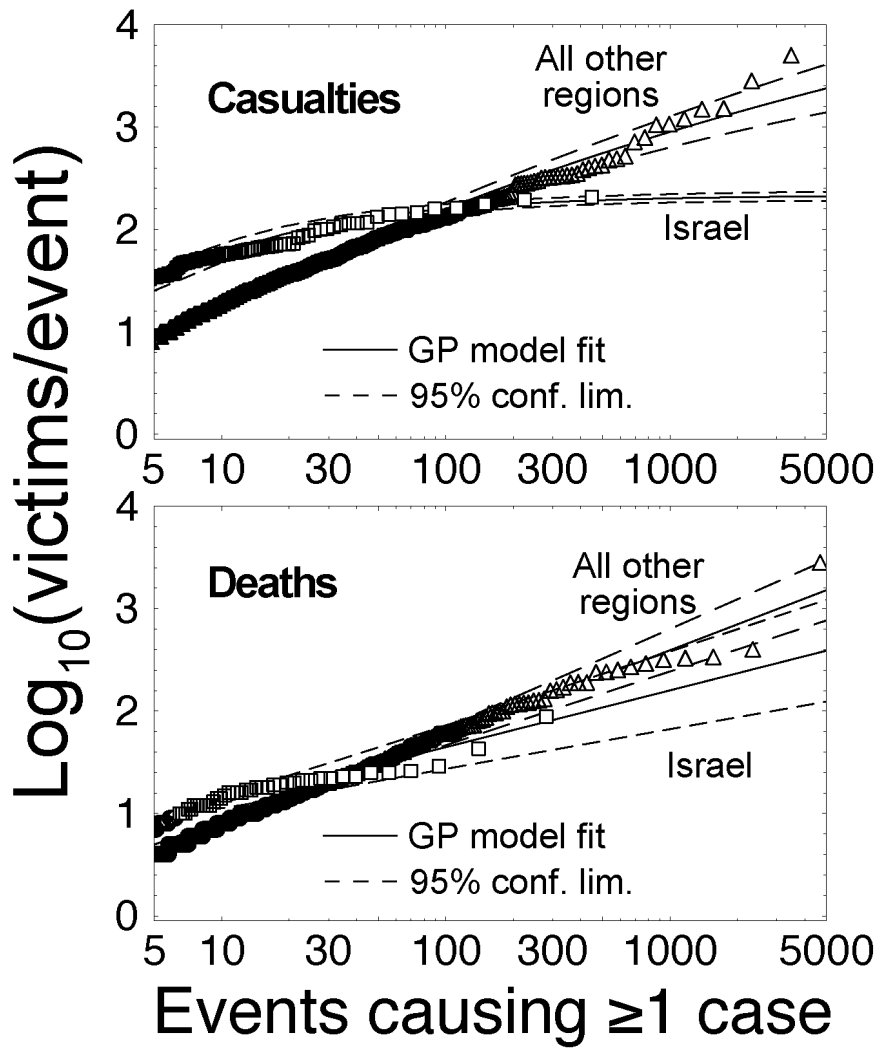

Figure 16. Generalized Pareto model fits to data on victims per terrorist event leading to $\geq 1$ case during 1968-2004 in Israel vs. all other regions, by endpoint (casualties or deaths). 

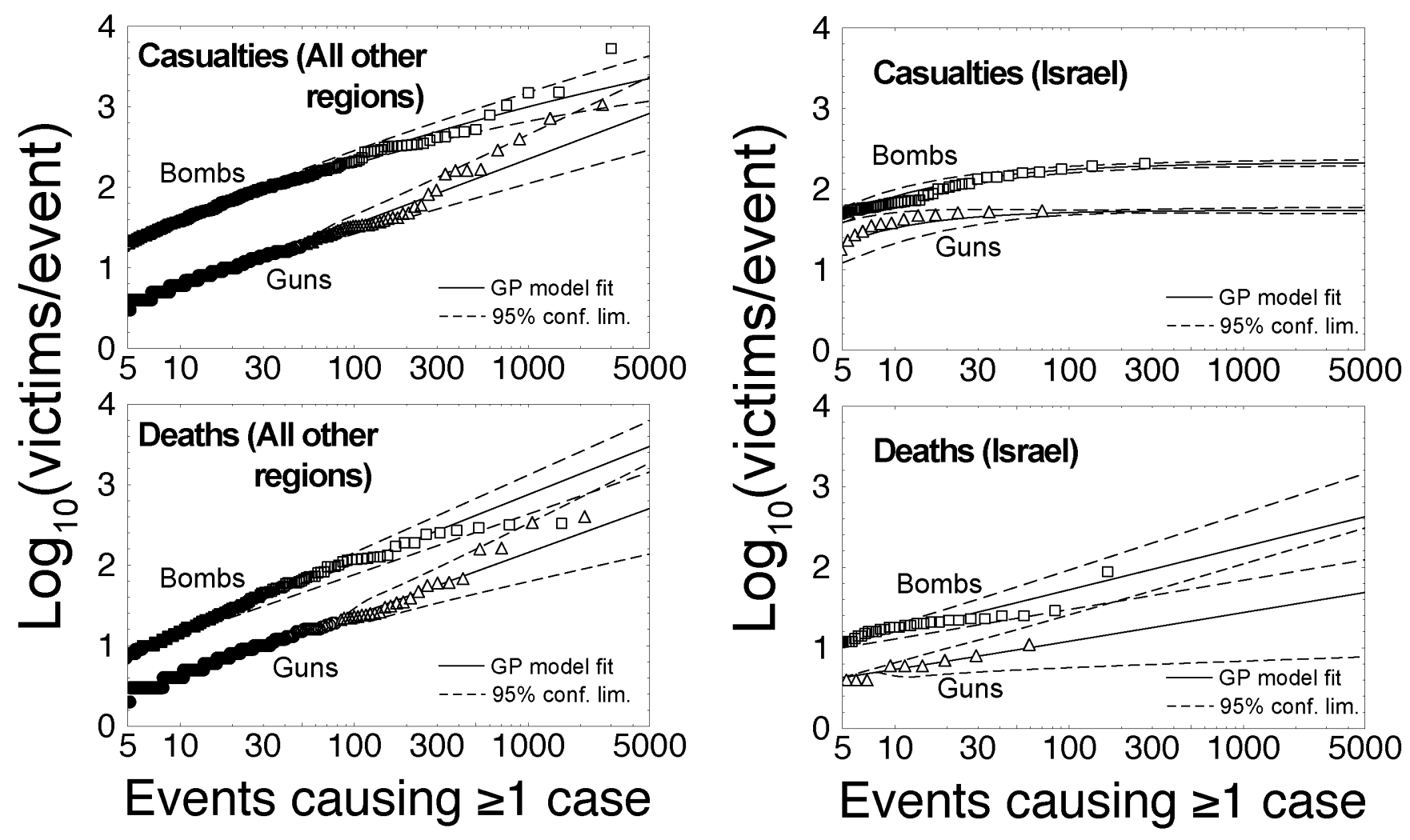

Events causing $\geq 1$ case
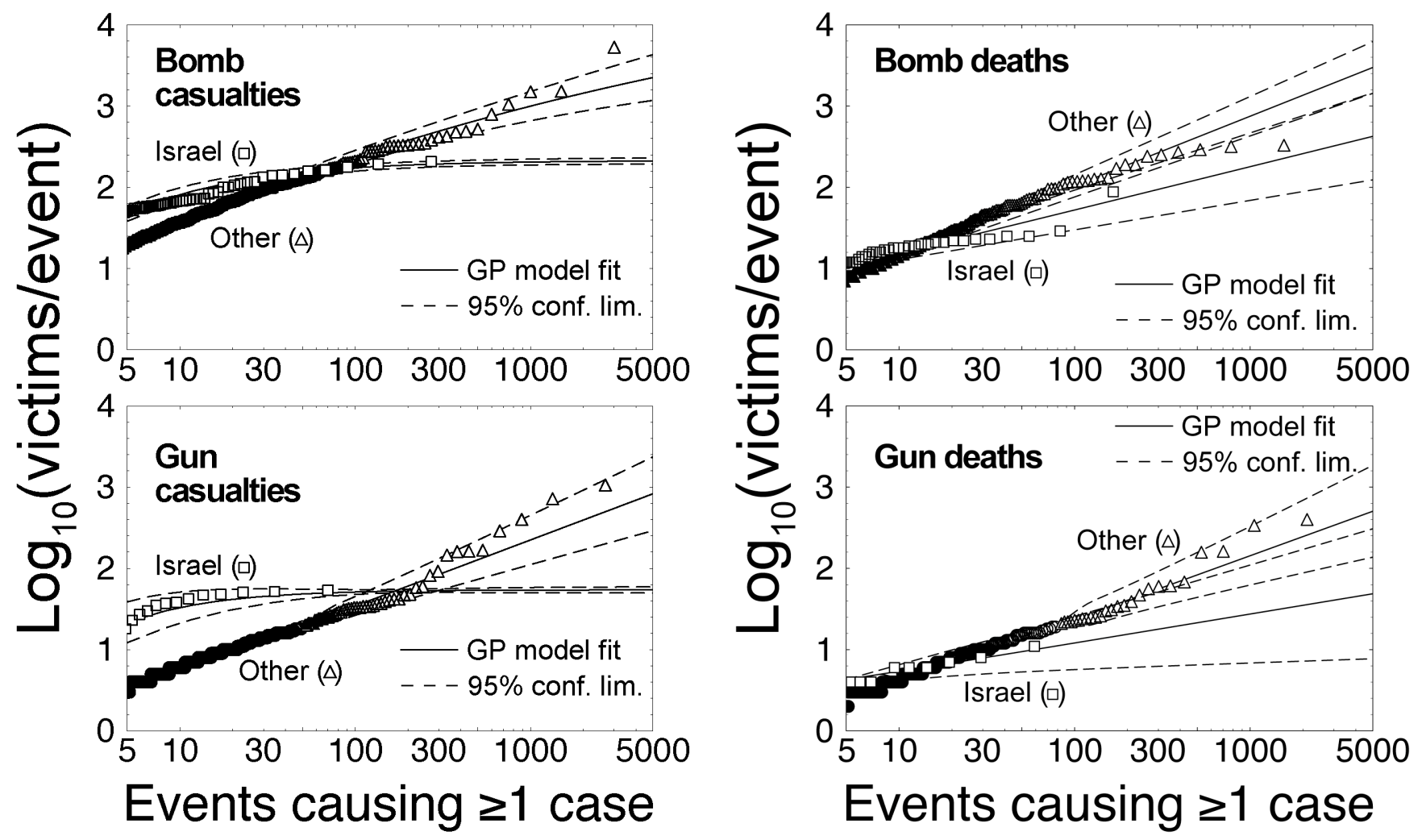

Figure 17. Generalized Pareto model fits to data on victims per terrorist event leading to $\geq 1$ case during 1968-2004 in Israel vs. all other regions, by endpoint and by weapon. 